\title{
Strategies of Marking Tense and Aspect among the Samor of Baringo County, Kenya A Morpho- Phonosyntactic Study
}

\author{
Daniel Kandagor Chepyegon, Dr. Josphine Khaemba, Dr. Phylis Bartoo
}

\begin{abstract}
This paper responds to a concern about the neglect of minor sub- dialects such as Samor in a wide range of research that focus on the analysis of tense. It is noted in this research that a majority of studies tend to focus on dominant languages leaving out minor sub- dialects. This paper focuses on the varying morpho- syntactic features in Samor a minor subdialect that mark tense. A linguist's desire is to investigate less studied dialects so as to describe their grammar. This paper responds to that concern. The paper contends that there is need to investigate the unique grammatical properties of minor subdialects since this aids in the preservation and understanding of the unique character traits that describe the people of this earth. One such character trait that describes people is the language they speak. The paper discusses the phonological features and strategies used in expressing tense and aspect in Samor. The research used the non- probability sampling using the convenience or opportunity sampling to sample one hundred utterances in Samor that were used to analyze the data. The paper used tape recording, interview and field notes to collect data. Non- probability sampling was also used to select the ceremonies that would be tape recorded. The data was transcribed, organized and analysed for tense marking strategies. Using Feature Checking Theory, this theory is important since it identifies the grammatical features that are used to mark tense. The theory proposes the following tense marking features: tense, person, number and gender. The theory proposes that such features are checked against any utterance to ensure grammaticality. In addition, the study used another theory in descriptive linguistics referred to as Grounded Theory. This theory enables a researcher to categorize data into analyzable units. The paper found out that Samor is a verb initial sub- dialect and morpho- syntactic features such as tense and aspect are marked in the verbal stem by attaching affixes. In addition, the paper found out that phonological processes such as tone, vowel lengthening and doubling play a key role in tense and aspect marking in Samor.
\end{abstract}

Index Terms - Syntax, phonological processes, morphological, features, tone, syllable, monosyllable and bisyllabic.

\section{INTRODUCTION}

The paper responds to the concern in the field of descriptive linguistics which observes that most studies on morphophonosyntax have tended to focus on major world languages leaving out minor sub- dialects such as Samor, the focus of the current study. Morpho- phonosyntax is the field in descriptive

Daniel Chepyegon, Egerton, University (Literature, Language and Linguistics)

Josphine Khaemba, Egerton, University (Literature, Language and Linguistics)

PhylisBartoo, Egerton University (Literature, Language Linguistics) linguistics that analyzes how human language is governed by grammatical rules. Dialects and languages differ, this then means that every human language has unique grammar rules that govern construction of grammatical sentences. According to Hacker and Baker (2009), the rules that govern sentential constructions include the following: tense and aspect (TA), derivational and inflectional properties of content words, concord and word order government. Since grammar rules differ, extensive research needs to be carried out so as to find out how different languages and dialects formulate the rules that govern grammatical utterances. The research sought to find out how the Samor sub- dialect marks tense and aspect part of grammatical rules that verbal expressions are assigned in grammar. In addition, a person may be in a position to perform even in languages that are not native to him or her. Therefore, for one to perform well in any language (first or second), s/he must know the rules governing language usage. Knowing the rules that are responsible for grammaticality in any language is a concern for any language teacher and linguist. The present study aims at investigating the way Samor a sub- dialect of Tugen marks tense and aspect.The tense of a verb is the time when the action takes place e.g. present, past and future (Coon, 2013). She adds that aspect refers to the way the grammar marks duration or type of temporal activity e.g. perfective, imperfective, progressive and non- progressive. Languages use strategies that differ from the way the English language marks TA.

These strategies include; using auxiliary verbs in combination with main verbs, use of affixes and tonal variations (Booij, 2005). This paper looks at the phonological processes that come into play while expressing tense and aspect in Samor. The Samor are a group of people who live in Baringo County of the Republic of Kenya.

\section{REVIEW OF RELATED LITERATURE}

The Samor sub- dialect is verb initial language and its unique characteristic is that it is uses phonological features in expressing tense and to express aspectual contrasts. The literature below looks at the characteristics of African languages particularly the Nilo- Saharan family of languages. According to Yip (2002) most African languages use phonological features such as tone. He adds that tonal languages do not rely only on morphosyntatic features alone in marking tenseand aspect as compared to a language such as English. In a research which looked at the interface between morphology and syntax in Chinese by Dai (1992b) he borrows from Anderson (1997: 152) and Zwicky (1990:201) who enumerate on three ways of analyzing a word. These ways are listed below:

\section{i. Phonologically}




\section{Strategies of Marking Tense and Aspect among the Samor of Baringo County, Kenya A Morpho- Phonosyntactic Study}

\section{ii. Morphologically}

iii. Syntactically.

He argues that if a word is viewed as a phonological unit, it becomes a prosodic domain in which certain automatic phonological rules may apply. Secondly, if a word is viewed as a morphological unit with inflectional characteristics, it becomes an object of morphology and finally if a word is an object of syntax, it is viewed as a syntagmatic unit. This assertion by Dai (1992b) is central in the current study that sought to understand TA marking in Samor. The research relied on the phonological and morphosyntactic features that are assumed to play a role in tense marking in Samor subdialect.

Stewart (2008) argues that an inflectional word, in word formation rules, is characterized by a formal structure change which may involve not only affixation but also other phonological changes e.g. metathesis, substitution, deletion among other processes. These formalisms: phonological, morphological and syntactic dictate how a morpheme is realized and how it relates with other components surrounding it (Stewart, 2008). He further proposes an assumption 'A- morphous' morphology which he borrows from Anderson, 1982; Zwicky, 1992: 338. The assumption Stewart (2008) states thus: "the word like unit, is the stem; derivation is a lexicon- internal property and inflection falls outside the lexicon". He enumerates that inflection rules represent knowledge not of particular words, but rather of the form taken by words as a consequence of the syntactic structure in which they appear. Stewart (2008) concludes thus: "the model of grammar, entails the split morphology hypothesis an assumption he borrows from Permutter, 1988; Booij, 1993 and Beard, 1995".

The assumption is that inflection is "in" the syntax and derivation in the lexicon (word). These authors furthermore state that there exist attributes that belong to inflection and those that fall under derivation. These attributes are summed up as word formation rules. The inflectional rules specify structural changes which may involve not only affixation but also other phonological changes such as: metathesis, substitution and deletion (Stewart, 2008). This is the basis of the current study, the argument that TA marking may go further than morphosyntactic features. It is evident that phonological processes sometimes come into play. One objective of this research is to analyze the role of phonological processes and prosodic features in TA marking. This present study affirms that it is not only the morphosyntactic features that mark TA; there are also cases whereby TA marking relies on phonological and prosodic features e.g. insertion, vowel lengthening etc.

Phonological processes concern themselves with features that fall under the realm of sound. According to Bybee (2003), a phoneme is a sound segment or a meaning distinguishing sound separated by slash marks. She further argues that languages may have similar phonetic segments but treat them differently. In addition, she says that above the segment is the syllable; a combination that must contain a vowel or vowellike sound represented as CV. McMahon (2002), argues that phonemes have distinguishing features. She adds and states: "Phonetics provides the means to describe the phones (sounds) of language, showing how they are produced and how they vary". This means that a feature distinguishes one phoneme from another. The list below demonstrates some of the features that distinguish on phoneme from another:

$$
\begin{aligned}
& \text { i. Voicing (+Voice or -Voice) } \\
& \text { ii. Nasality (+ Nasal or -Nasal) } \\
& \text { iii. Back (+Back or -Back) }
\end{aligned}
$$

The features listed above show that phonemes vary from on language to another. Moreover, it demonstrates that certain phonemes are uttered with voice, others minus voicing. In her discussion of phonological processes, Bybee (2003) classifies phonological processes as follows:

a. Feature changing rules e.g. Assimilation - Features can become assimilated or dissimilated. This occurs when vowels that occur before nasal consonants within the same syllable become nasalized or a feature segment or suprasegment spreads to surrounding segments.

b. Feature adding rules- Features such as: deletion- this involves the loss of a sound segment or suprasegment when morphemes or words are combined together. Phoneticians refer to it as syllable shortening and consonant deletion.

c. Epenthesis occurs when a sound segment (vowel or consonant) is inserted into a word to make the structure of the word conform with the language's syllable structure.

d. Movement rules (Metathesis)- reordering of segments.

The present study sought to find whether phonological processes of any kind play a role in TA marking in Samor. For instance, Towett (1975) in a study of Kalenjin linguistics discovered that vowel lengthening and vowel insertion played a role in marking the perfect progressive aspect. According to Crystal (2003) length can be displayed in the vowel or the consonant. English distinguishes long and short vowels by using the adding a colon after the long vowel e.g. the sound /i/ and /i:/. The two sounds are used to contrast when the words 'bit' and 'beat'. In Kalenjin Towett (1975), two options are possible. The first one is whereby a vowel is added (doubled) i.e. epenthesis or a vowel is deleted. This is when a speaker is referring to a recently completed action (past perfect) and a completed action in the past in the distant time. For example: Ki- ka: am \{ki- REC PST ka:- PERF- am eat\} 'I had eaten' and Ki- kaa:- am' \{ki- DIS PST kaa:- PERF am eat $\}$ 'I had had eaten'.

\section{a) Phonological Processes}

Phonological processes in linguistics fall under two categories i.e. segmental and non- segmental features. The author McMahon (2002) argues that the phoneme is a sound segment but he adds further and says that there are also other features above the segment which we refer to as suprasegmental or prosodic features. In a classification of prosodic features, Fox (2000) identifies the following suprasegmental features: pitch, stress, segment length, tone and intonation. According to him, pitch is the glide from high (H) to low (L) as someone is speaking but stress/ accentuation is whereby a syllable is louder and higher in pitch than the other syllables in a word. As a result, the syllable is perceived as prominent. The other prosodic feature according to him is segment length i.e. vowel lengthening. He expounds that features that are identical in manner or place may differ in length. 
Tone is the variation in pitch to contrast meaning (Fox, 2000). The author Yip (2002) argues that a language is a tone language if pitch of the word can change the meaning of the word. He further states that Cantonese a highly tonal language identifies six different pitches. Linguists use diacritics to distinguish tonal marking in a sound. Bird's (1999) analysis of Niger Congo family of language and Zwart's (2003) analysis of the phonology of Endo give the following system of diacritics used to mark various tones. See table 3 below.

Table. 3 Tone Marking in Endo

\begin{tabular}{|l|l|l|}
\hline $\begin{array}{l}\text { TONAL } \\
\text { CATEGORY }\end{array}$ & ABBREVIATION & $\begin{array}{l}\text { DIACRITIC/ } \\
\text { EXAMPLE }\end{array}$ \\
\hline $\begin{array}{l}\text { UNMARKED } \\
\text { LEVEL TONE }\end{array}$ & - & $\mathrm{a}$ \\
\hline HIGH TONE & $\mathrm{H}$ & $\mathrm{á}$ \\
\hline LOW TONE & $\mathrm{L}$ & $\mathrm{à}$ \\
\hline MID TONE & $\mathrm{M}$ & $\overline{\mathrm{a}}$ \\
\hline LOW HIGH & LH & $\mathrm{a}$ \\
\hline HIGH LOW & HL & à \\
\hline EXTRA HIGH & $\mathrm{XH}$ & $\ddot{a}$ \\
\hline EXTRA LOW & $\mathrm{XL}$ & $\mathrm{a}$ \\
\hline
\end{tabular}

Note. Examples of Tone Marking Abbreviations in Niger Congo and Endo. Adapted from Zwart (2003) and Bird (1999).

According to them, tone is marked either as high, low, level or a mixture of high low, low high etc. The diacritics help to specify the kind of tone being marked. Bao (1990) asserts that tone can consist of register and contour. The voice quality produced by a specific physiological constitution of the larynx. He states that register tone languages focus on the height of the syllabic pitches and not the direction in which they move i.e. contour. A majority of languages according to Bao (1990) and Bird (1999) are tonal. They argue thus: "languages whereby word meaning or grammatical category are dependent on pitch level are known as tone languages." They sum- up by saying that the unit carrying the tone is the tone bearing unit (TBU). The assertion by Bao (1990) and Bird (1999) is what drives the current research i.e. whether some words distinguish grammatical category by merely using tone. The study adapted Zwart's (2003) and Bird's (1990) tone abbreviations and diacritics to understand Samor the current sub- dialect in focus. The abbreviations and diacritics were essential in distinguishing meaning based on tonal marking. The current research was also motivated by findings by Bird (1999) which observed that in Dschang language spoken in Cameroon, grammatical meaning is distinguished chiefly by tone.

\section{RESULTS, FINDINGS OF THE STUDY}

The research found out that Samor is tonal. This means that TA marking doesn't rely solely on affixes that are preverbal or post verbal. This sub- dialect employs other strategies in marking TA. The research found out that long vowels may be doubled to express some aspectual contrasts. Tone is key in Samor in expressing the various tense categories. Tone means that the pitch of the word can change the meaning of the word (Crystal, 2008). Samor is a tone language. This is because the pitch of individual vowels at the syllable level contrast the meaning of words. The basic argument in Samor is that tone does not only distinguish meaning of words which we classify as lexical function. In Samor, tone goes further and contrasts grammatical function. In this sub- dialect, tone marks grammatical features such as TA. According to Yip (2002), languages may contrast as many as six main tones. These tones can be level, low, high, low high, high low and downstep.

These tones have unique marks that distinguish one from the other; for instance, the level tone is marked with a dash diacritic mark placed above the vowel. The high and low tone is marked with commas placed above the vowel. These diacritic marks also called prime marks. They slant to the left to identify low tone and slant to the right to show a high tone. Double prime marks illustrate an extra high or low tone. A down-arrow illustrates a downstep tone. The low high tone is marked with a "v" sign placed above the vowel whereas a caret (an inverted "v") highlights a high falling tone. Samor contrasts high and low tones plus a combination of the same. Tone in Samor is nearly always transcribed on the syllable nucleus which is usually the vowel. The tone bearing unit in Samor is the vowel. This is because the vowel is the most sonorous segment in a monosyllabic word. Samor monosyllabic words contain only one tone. However, bisyllabic words are made up of two tones. In Samor, the base form of the verb may have either high, low or high low tone. However, if the tone is varied, the meaning changes as well. This study borrows the unique tonal marking from Zwart (2003) and Bird (1999). See table 3 pg. 22 tone marking in Endo.

\section{b) Tonal Marking in Present Time}

In Samor, the indicative base forms of the verb take a low tone whereas the imperative counterparts take a high tone. Tone distinguishes the indicative from the imperative forms. The indicative base verb highlights events taking place in the present moment. The indicative form has a low (L) tone whereas the imperative contains a high $(\mathrm{H})$ tone. See extract 21 coded S2BT of the word 'nyì' which has been used in the imperative and indicative form.

Extract 21

S2BT: Kongoi pastor. Amacheakonokripot ne kararanagopomurenchu. Ichek ko kikineetichekngalektugulchebotegis, ngalekcheboamu nee sikeleni chi ko muren. Kikimwachikelenchingotkobiit age tugulengichek ne kotinyeingalekchebolakwandi ko mawalei chi ne uunoto. Kiamwochialenchimuren ko ma mayweek, muren ko ma moo kityo. Kiamwochialenchiingongoomiit age tugulasikaronkelenionchumurenik.

Kiakurbiikchekonyitotinkongalalchiichekara mamacheatesyingalekchechang. Ara nyiy age tugulng' alechoee. Nyiy!Komie. Ye kimakasng' alekchebomenjo ko makukaseialak. Kongoi.

Translation

Thank you pastor. I want to give you a good report concerning the young men. We taught them everything concerning respect, everything concerning why someone is said to be a man. We 
told them that if one among them will be found whom people are saying he still has childish behaviour, such as him, no one can change. I told them that a man is not alcohol, a man is not only the stomach (metaphor- greed). I told them that each one should be clever so that tomorrow people will say, here are men. I invited all respectful advisors to talk to them. Therefore, I don't want to add a lot. So each one chew those words. Chew! Properly. If they didn't listen to the words/ teachings in the circumcision chamber, they won't hear any other. Thank you.

In the example (a) S2BT and (b) S2BT below, we can see the way tone distinguishes sentence type.

(a) S2BT- Nyìy- 1 [low tone]

Chew (indicative)

(b) S2BT- Nyíy- h [high tone]

Chew (imperative)

In the examples (a) S2BT above, low tone on monosyllabic verb 'nyiy' marks the indicative mood whereas a high tone on the mora of the verb 'nyiy' highlights the imperative mood, see example (b) S2BT above. However, in bisyllabic verbs each vowel has its unique tonal marking depending on the speaker's voice variations. A speaker varies the force s/he exerts on the mora based on the meaning s/he wants to express. See example (c) S2BT below, the each individual vowel picks a different tone to express a present activity.

(c) S2BT- àkónók- lhh

1PSG a- RV kon- PL SUFF ok

I want to give you.

In Samor, the present is sub- divided into three categories: indicative, subjunctive and conditional. The present indicative bears HLL tones. These are actions that take place at the time of speaking. The dialect has a unique characteristic whereby all person number prefixes always have a characteristic high tone in most cases to emphasize the doer of the action. Study the examples from the data in extract $2 \mathrm{pg}$. 61 coded S2PS (A).

In examples (h) S2PS (A) and (i) S2PS (A) below, we can see number and person marking in the present indicative. The tone is hll

(h) S2PS (A)- á- kèr- è (hll)

1PSG SUB MRK á- RV kèr- FV è

I see

(i) S2PS (A)- kí- kèr- è (hll)

1PPPL SUB MRK kí- RV kèr- FV è

The examples (h) S2PS (A) and (i) S2PS (A) above, the prefix

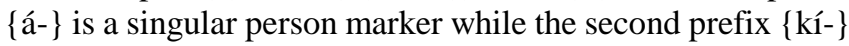
is a plural marker. This means that an incident was witnessed by a singular entity and more than one person. However, if we want to explain that a second person witnessed an event, the sub- dialect uses \{ó- $\}$ prefix. See example in extract 22 below of the word "okeren".

Extract 22

S4AP- Engtugulmwaesirutikkole, olosuinen, otienokerenitikwokmwaitasimokasngalchematoreto k.

Translation

In all, the holy Bible/ word of God states that we praise him, sing and close your ears with oil so that you do not hear things that are not good.
In the example coded (e) S4AP below, we can see how second person can be addressed.

(e) S4AP - Ó- kèr- èn

2PPL SUB MRK ó - RV kèr- PREP èn

Close with.

Samor lacks a subject marker for third person. Third person is usually identified if the speaker mentions the doer of an action (subject) or when he/she uses a personal pronouns. As such, third person is marked using the theta symbol $\{\varnothing\}$ in this study. This is to show that it is an empty category. See the example of the word "kere" coded S3PS sourced from extract 3 pg 66.

S3PS - Ø- kèr- è

3P SUB MRK Ø- RV kèr- FV è

He sees.

The distinction between a high $(\mathrm{H})$ and low tone $(\mathrm{L})$ is amorphous or arbitrary. This is because tonal variation is based on the consonant sounds that precede or come after the TBU.

\section{c)Tonal Marking in the Present Subjunctive}

This type of tense is expressed tonally. The present subjunctive has the progressive suffix marker $\{-\mathrm{e}-\}$ but sometimes the sub- dialect omits the progressive suffix marker $\{-\mathrm{e}-\}$ if the utterance is in the subjunctive mood. The suffix $\{-\mathrm{e}-\}$ progressive suffix comes after the root verb. The example (h) S5CG and (i) S5CG in extract 23 below distinguishes the present indicative from the present subjunctive.

Extract 23

S5CG ‥kas anyon ra, mwa age tugulile, akasenga' lechubo ra. Bagachkiy ne ileniakas!

Translation

.... Hear then today, everyone to say, I will hear these words today. Leave doubts like saying can I hear!

(h) S5CG- Á- kàs- è (HLL)

1PSG SUB MRK á- RV kàs- FV è

I hear

(i) S5CG- á- kás! (HH)

1PSG SUB MRK á- RV kás

Can I hear!

In example (i) S5CG, the high tone on the nucleus of 'kas' and the lack of the $\{-\mathrm{e}-\}$ a progressive marker changes the utterance into the subjunctive. Example two is a polite request to do something in the current time. Study extract 24 below.

Extract 24

S5CG $\quad \cdots$.akbichchelenei, nda

Translation

akasng' alechu ra. Kongoimising

'And people who say, I wish to hear these words today. Thank you very much.'

In example (j) S5CG, the present conditional is marked with a high tone on the base verb plus the addition of a conditional

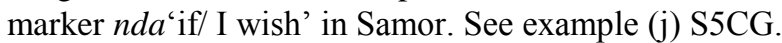

(j) S5CG - Ndà á- kás (LHH)

COND nda-1PSG SUB MRK á- RV kás

If I can hear.

In example (j) S5CG above, the tone is lhh to express a conditional in the present. 


\section{d) Tone Marking in the Simple Past Tense}

The simple past in Samor expresses actions that have been accomplished a while ago, some few days ago and in the distant past. This tense category is marked apart using affixations to indicate the immediate past, recent past and the distant past. These affixes are $\{\mathrm{ka}-$, ko- and ki- $\}$ respectively. As can be seen in the examples coded EXF1, EXF3, EXF4, EXF6 and EXF11 below, the simple past tense, phonological feature tone also contrast these tense categories. The tone is hhl.

EXF1- Ká- á- sìr (hhl)

IMM PST TNS Ká- 1PSG SUB MRK á- RV sìr I wrote.

EXF3- Ká- í- sìr (hhl)

IMM PST TNS Ká- SG OBJ MRK í - RV sìr

You wrote.

EXF4- Ká- ó- sìr (hhl)

IMM PST TNS Ká- PL OBJ MRK ó- RV sìr

You wrote.

EXF6- Kó- á- sìr (hhl)

REC PST TNS Kó- 1PSG SUB MRK á- RV sìr I wrote.

\section{EXF11- Kí- á- sìr- hhl}

\section{DIS PST TNS Kí- á-1PSG SUB MRK á- RV sìr}

I wrote.

In the examples EXF1, EXF3, EXF4, EXF6 and EXF11 above, the morpheme $\{a ́\}$ is a singular person marker whereas $\{k i ́-\}$ is a plural person marker. On the other hand, the morphemes $\{1$ - and ó $\}$ are second person subject markers. The morpheme $\{1-\}$ marks singular person while the morpheme $\{$ ó is a plural person marker. As states earlier, the morphemes \{Ká, Kó and Kí\} in Samor mark the three types of past tenses that is, immediate, recent and distant past tenses respectively. See examples EXF1, EXF3, EXF4, EXF6 and EXF11 above. In these three types of past tenses, the tone is normally $\langle\mathrm{hhl}\rangle$ in all the three types of past tenses, that is; immediate, recent and distant past.

\section{E) Phonological Processes in Aspectual Contrasts}

As had been stated earlier, aspect expresses the way an action is performed. The current research found out that apart from affixations marking aspectual contrasts, there are also cases whereby phonological features come to play. These features are tonal marking, vowel lengthening and doubling. According to Yip (2002) if pitch of the word can changes the meaning of the word. Then such a language is classified as a tone language. Such languages uses a range of tones of such as low, high and level. These tones vary from one vowel sound to the other. The other phonological feature that is vowel lengthening according to Towett (1975) and Crystal (2003) state that length can be displayed in the vowel or the consonant. In Samor, vowel lengthening involves distinguishing a relatively long and short vowels. These vowels are distinguished by using a colon after the long vowel. The other phonological feature in Samor involves adding another vowel to express the way an action has been done. As had been discussed earlier aspectual contrast expresses either a perfect or imperfect situation.

\section{f) The perfective}

Samor distinguishes two aspectual contrasts i.e. perfective and imperfective. In this sub- dialect, aspect appears inside tense post verbally using the suffixes $\{-\mathrm{e}-\}$ and $\{-\mathrm{i}-\}$. The first example type that is perfective, denotes complete actions. The perfective is seen as unitary and without referring to the flow of time. Sometimes the perfective is marked by the past tense. In addition, the perfective is viewed as non- ongoing and hence a completed action or activity, some other research refer to the perfective as the aorist. The examples EXF4 and EXF6 above illustrate the perfective aspect. The perfective express a completed action. Such actions are marked by high tone placed in the preprefix, the person marker morpheme $\{-a ́-\}$ and the base form of the verb. In Samor, the mora carries the tone. See the extract 25 below.

Extract 25

S4AUBG $\quad \cdots$ Kaakeranee ale

ngotkenyoruwarekchookoyaeitugunchemiach, ko agot ko uunoto, ko kararankesaaJehovaasikobiitkoberurbarnotikchoo. Translation

I have seen myself that if we get our lambs (metaphor) doing good things, so even in that way, it is prudent that we pray to God so that (he) blesses the youths.

In example (a) S4AUBG below, <hhl> tone expresses the perfective.
(a) S4AUBG- Káá- á- kèr [hhl]
1PSG á- RV kér
I saw.

The perfect in Samor means an action has taken place 'up to now'. Perfect actions are expressed in Samor using three phonological processes. These processes are as follows:
a) Tonal marking
b) Vowel lengthening
c) Vowel doubling

These processes are shown in the example (b) S4AUBG below.

(b) S4AUBG - Ká- à:- kèr- hll

PST TNS Ká- 1PSG PERF à:- RV kèr

I have seen.

In the example (b) S4AUBG above, the perfect action is marked by the lengthening of the first person and perfect aspect marker $\{$ à:- $\}$ and also by a high tone on the prefix followed by a low tones. In expressing an action that has been accomplished by a second person, the tone is high in the first prefix followed by a high tone. For example, in extract 26 below, the speaker asserts that he saw his car being repaired. See extract 26 below.

Extract 26

MCE8 ‥ Kakeragotkariinyo ne kakichoobeisikeboiseykeiptugukengsiro.

Translation

I even saw my car being repaired so that they can bring some items from the market.

In the example below coded MCE8, the prefix \{ká-\} has a single vowel unlike example (b) S4AUBG above. The tone is $<\mathrm{hl}>$ to highlight that the action was being accomplished by a second and third person. 
MCE8- Ká- kèr- hl

PST TNS Ká- RV kèr

He saw.

However, in case the reporter wants to indicate that the second person has just seen an action, the initial vowel in the preprefix is doubled and the tone changes to hhlh. See extract 27 below.

Extract 27

QOS- Ilenii nee ye

imacheimwaailekoitariyaekiyengbetusiekch e ma lo missing?

QOE- How do you state that you just finished doing something in the recent past?

R01S- Alenikaakokerlakwee.

RO2S- Aleniikaakeekerlakwee

Translation

RO3S- Koaaam.

RO1T- I will say they had seen the child.

RO2T- I will say we had seen the child.

RO3T- I had eaten.

In the examples RO1S and RO2S below, the word 'kaakoker' and 'kaakeeker' make use of pitch variation and vowel variation.

RO1S - Káá- kó- kér- hhlh

PST PERF Káá- 2PSG kó- RV kér

He has seen.

In example RO1S above, the tone is <hhlh> so as to mark a completed action in the recent past. Vowel doubling is Samor express the perfective in a singular and plural entity. The vowels are doubled in the preprefix plus the second prefix before the base verb. See example RO2S below.

RO2S - Káá- kèè- kér- hhlll

IMM PST TNS PERF káá- 2PPL kèè- RV kèr

We had seen.

In example RO2S above, the speaker states that other people and herself had seen the good behaviour of the newly weds. In Samor, the prefix $\{k e\}$ marks plural person. In example RO2S above, the aunt of the newly weds plus other people in their neighbourhood had seen that the newly weds were people with a noble character. Extract 28 below, highlights an action that was witnessed in the recent past. The vowels [-o-] and [-e-] are doubled and the tone is <hhlll>. See example (c) S4AUBG below of the verb "kookeeker".

Extract 28

S4AUBG

...Angen

kookeekerachektugulagopoateptaabwarechu.

Translation

I know that all of us had seen the good behaviour of our lambs (metaphor of youth).

(c) S4AUBG - Kóó- kèè- kèr- hhlll

REC PST TNS PERF kóó - 2PPL kèè- RV kèr

We had seen.

Apart from vowel doubling, the tone is high in the first preprefix and lowers in the subsequent syllables. In Samor, vowel lengthening in combination with tone is the most common method of highlighting actions and activities that have just been accomplished. The preprefix and the person prefixes preceding the root verb are lengthened. Vowel lengthening can be seen in the following types of perfect.

\section{g) Perfect of result}

This type of perfect indicates that someone has just accomplished something. A good example of such type of perfect is seen in a case whereby someone wants to demonstrate that someone has just arrived. The tone marking is almost always high and is marked by the mora. See extract 29 below.

Extract 29

QNS- Ileni nee ye imacheilekaitariyaekiyengsait ne negit?

QNE- How do you express that you have just finished doing something in the immediate past?

RN3S- Kaait

RN4S-Kaaaít

RN5S- Kakaaawe

RN6S- Kakakaaamwa

Translation

RN3T- I have arrived/ reached

RN4T- I had cut the tree.

RN5T- I had gone

RN6T- I had had said.

In example RN3S below, the interviewee argues that she has arrived. Since this is an action that has just occurred, it highlights the present perfect in Samor. However, example RN4S below, the action highlights the past perfect.

RN3S- Ká- á:- ít- hhh

IMM PST Ká- 1PSG PERF á:- RV ít

I have arrived

RN4S - IMM PST Ká- 1PSG PERF á:- RV ít

Ká- áá:- ít- hhhh

I had arrived

In example RN3S above, the sound $\{\mathrm{a}\}$ is lengthened but there is no doubling as in example RN4S above. The tone example RN3S is <hhh> whereas in example RN4S above, the tone is $\langle\mathrm{hhhh}\rangle$.

\section{h) Perfect of recent past}

In this type of perfect, the speaker expresses that s/he did something in the recent past. The vowel is lengthened in the preprefix and prefix as seen in the example RO3S below but the difference is the use of $\{$ kó- $\}$ preprefix that marks the recent past in Samor.

RO3S - Kó- áá:- ám- hhhh

REC PST kó:- 1PSG PERF áá:- RV am

I had eaten.

In the example RO3S above, the tone remains as $<\mathrm{hhhh}>$.

\section{I) THE IMPERFECTIVE}

In the previous discussion, we indicated that the perfect expresses completed and non- ongoing actions that have been completed in the past. On the contrary, the imperfective in Samor highlight activities that unlike the perfect are ongoing, habitual and continuous in nature. This type of aspectual contrasts in Samor is marked by $\{-\mathrm{e}-$ and $-\mathrm{i}-\}$ suffixes which come after the base form of the verb. Moreover, other phonological properties come into play in expressing the imperfective aspects in Samor. Below are the examples of imperfect situations in Samor. 


\section{A. j)The habitual}

This type of aspectual contrast expresses situations that last for an extended period of time. Accordingly, they are said to be actions that don't seem to end. This is common if one wants to state that someone has been doing something for a long time. In the extract 30 example (d) S4AUBG below, someone is described as an habitual smoker. Extract 30

S4AUBG‥Am lagokalak, changchepetyotin, changcheeeimayweek, changchekuleisigaresiek. Ago engtugul, ko matileikiyatepto ne ya.

Translation

... Concerning the other children, there are many who are lost, there are many who drink alcoholic beverages, there are many who smoke cigarattes. However in all, bad behaviour doesn't help in any way.

The verb 'kulei' example (d) S4AUBG below is a combination of the base form 'kul' and two suffixes.

(d) S4AUBG - Kùl- è- ì- 111

RV kùl - IMPERF è - FV ì

(He/she) smokes

The example (d) S4AUBG above exemplify that the aforementioned person smokes. The suffix $\{\mathrm{e}\}$ marks habitual activities. In Samor, all habitual actions are marked by adding the $\{-\mathrm{e}-$ and $-\mathrm{i}\}$ suffixes after the root verb and also by lowering the tone.

\section{B. l) The progressive}

The second type of imperfective aspect in Samor is the progressive aspect. These are events as stated earlier that are ongoing. Samor uses tone to distinguish habitual actions from continuous situations. In the example (f) S4AUBG below, tone is the only distinguishing factor since the verbs marking habits and the continuous aspect remain the same. Consequently, a high tone in the base verb and the $\{-\mathrm{e}-$ and $-\mathrm{i}-\}$ suffixes changes an habitual action into a continuous activity, See example (f) S4AUBG below.

(f) S4AUBG - Kúl- é- í- hhh

RV kúl - IMPERF é- FV í

(He/she) is smoking

Another way of demonstrating that someone was continuously smoking in the past is by adding $\{\mathrm{ka}-, \mathrm{ko}$ and $\mathrm{ki}\}$ prefixes to the base of the verb. The example (g) S4AUBG highlights a situation that was ongoing in the remote past.

(g) S4AUBG - Kí- kúl- é- í- hhhh

RV kúl - IMPERF é- FV í

(He/she) was smoking

In Samor, \{ka-, ko and ki\} are allomorphs marking time variations. See the data in appendix 6 pg. 201 coded RR2S, RR3S and RR4S which shows the usage of the three allomorphs of time in Samor.

\section{C. m) The progressive of persistent result}

This type of progressive aspect enumerates a situation that has been persisting for a long time. To achieve this, the subdialect uses an elongated remote past tense preprefix [ki-] and the vowel in the second prefix coming after the preprefix is doubled. See extract 32 in the example coded RU1S.

Extract 32

\section{QUS- Ileni nee ye imacheimwaki ma ingenilekikaayae chi kiyengbetut/sait age tugul?}

QUE- How do you say youdidn't know a person had been doing something on any particular time?

RU1S-Alenikikaabireichepyoseetnyin?

RU2S- Alenikikikaabiriechepyoseetnyin?

RU3S- Alenikikaatileiketit?

Transalation

RU1E- I will say you mean he had been beating his wife.

RU2E- I will say you mean he had had been beeting his wife. RU3E- I will say you mean he had been cutting a tree.

In example RU1S below, actions that persist are marked with $<$ hllhhh $>$ tone and by using the $\{\mathrm{ki}-\}$ prefix.

RU1S- Kí:- kàà- bír- é- í- hllhhh

DIS PST kí:- PERF kàà- RV bír- IMPERF é- í FV

$\mathrm{He} / \mathrm{she}$ has been beating.

Moreover, to state that the beating had persisted in the more remote past, the sub- dialect reduplicates the $\{\mathrm{ki}-\}$ preprefix. However, the sentence remains virtually the same. See example RU2S below.

RU2S - Kí- kí:- kàà- bír- é- í- hllhhh

DIS PST Kí- kí:- PERF kàà- RV bír- IMPERF é- í FV

$\mathrm{He} / \mathrm{she}$ had been beating.

\section{D. m) The non-progressive}

The non- progressive in Samor expounds on a single duration of an action. The non- progressive is used in describing a series of events that a person or a thing was doing. This category is marked by using the prefix $\{k u$ :- $\}$ that precedes the base verb. The tone is $\langle\mathrm{hh}\rangle$ in the $\{k u ́\}$ narrative prefix and the root monosyllabic action verb. See extract 33 below.

Extract 34

S2UNBG -Ayani ale eng ra moikutilakwa age tugulkoleatepiekomieengatepto ne kararan. Kongoileiyeeenglagokapnganasaniamuatgai kora koyaeacheksigikkeboiboitumising. Ara maema, amachengiwekotung, iweiripsandenoo aka some ale ingoiberurokJehovaaklagokchewerikaktibiik.

Kongoimising.

Translation

I believe that as from today, every child will decide to maintain good character. Thank you to all the children of this ridge, since at all times you have made us parents to be very happy. Therefore uncle, I want to request that when you go to your new home, take care of your husband, I also pray that God may bless you with children; both boys and girls. Thank you very much.

See example coded S2UNBG below.
(a) S2UNBG - Kú:- tíl- hh
NAR PREF kú- RV kól
(He/she) decides

The example (a) S2UNBG above indicates the nonprogressive aspect in Samor.The narration prefix enables a speaker to show explain what someone is doing. To achieve the narrative effect, the speaker must lengthen the vowel and raise the tone. In addition, progressive situations in a narrative context are achieved by using $\{\mathrm{a}-\}$ for singular entities and $\{\mathrm{ke}-\}$ for plural. They highlight what someone says or does. See example (k) S5CG below. 
(k) S5CG- Á- kás- hh

1PSG á- RV kás

I hear.

Anther similar example is seen in extract 35 below.

MCE9: Amacheasomok ale amukiribesait, ko amacheamwa

ale, amacheketountuyeenebobetutnebo ra engsaet. Asome Pastor Kipsometkotowechtuyoniengsaet. Karibu pastor.

I want to request that since we want to keep time, I want to say that we need to begin the today's meeting with prayer. I request pastor Kipsomet to begin for us the meeting in prayer. Welcome pastor.

See example below coded MCE10.

MCE11- Á- mwá- hh

1PSG á- RV mwá

I say.

The example MCE10 above shows what someone heard or said something. The two examples elaborate on how narration is achieved in Samor. The actions are progressive since the hearer cannot quantify at what time did the speaker stop talking or listening. In the event that the speaker wants to demonstrate that an activity extended in the past, the sub-dialect uses the past tense marker $\{\mathrm{ki}\}$ and the progressive marker $\{\mathrm{e}\}$. The example in extract 36 below of the utterance 'kimwaei' which elaborates an imperfect action. Extract 36

S2PG

(M):

Biiktugulchekochamobwaakootnyuuamache ale ingoberurookJehova ne mii barakKipsengweet. Kongoi, kongoiamukobwaaasikeboibochiinwarwani. Ang inyeeJelagat, kimwae nee wee warwani? Kimwaei chi kengkole, kiameiatep. Kong' eteiyanitepkomie, aramekereanyunberurto ne te ne kaaiibu kai.

Translation

To all of you who accepted to come to my house (where I was married), may the God who is in heaven bless you. Thank you, thank you because you accepted to come so that we can all celebrate (be happy about my lamb- metaphor). And for you Jelagat, What can we say my lamb? Long ago people said, good behaviour is eaten. Ever since you accepted to stay well/ to be well behaved, don't you now see the amount of blessing you have brought us/ to this home?

The example S2PG (M) below of the verb "kimwaei" an imperfect action. This is an action that has not been completed.

S2PG (M)- Kí- mwá -è -ì -hhll

PST Kí- RV mwá- IMPERF è- FV ì

He was saying.

\section{E. n) Emphatic Progressive Aspect}

This is a unique type of progressive in Samor whereby the speaker puts extra emphasis to what s/he is saying. In Samor, this type of aspect is achieved by inserting an alveolar fricative /s/ and a palatal approximant /j/ in between the perfect aspect vowel /i:-/ and the imperfect aspect progressive vowel marker "-e-". Once this done, the utterance becomes emphatic in nature. The listener is able to perceive that the person speaking is indeed doing that particular activity at the time of speaking. Example (1) S5CG below of the verb 'osirisyei' provides an example of emphatic aspect in Samor.
The chief guest was encouraging the university students to go to to university and write down what they are being taught by their lecturers.

(1) S5CG- ó - sír- í:sy- ê- ì -hhh(hl)l

1PSG á -PRES RV sír- PERF í:- EMP IMPERF ASP sy- ê$\mathrm{FV}$ ì

I am writing.

In addition, emphatic stress can be expressed in the three allomorphs of Samor as can be seen in the example in extract 37 below.

Extract 37

QCCS- Ileni nee ngimacheile mii boisiet ne keyae ye ingalali?

QCCE- What do you say when you want to say you were doing something at the time of speaking?

RCC1S- Aleni kami asirisyei

RCC2S-Aleni koasirisyei

RCC3S-Aleni kasirisyei

RCC4S- Alenikiasirisyei

RCC5S- Sirisyei

RCC1E- I will say I was writing

RCC2E- I will say I writing (a few days ago)

RCC3E- I will say I was writing (in the recent time)

RCC4E- I will say I was writing (in the distant past)

The action verb 'sirisyei' can combine with the three time allomorphs $\{\mathrm{ka}-$, ko- and ki- $\}$ as stated earlier to highlight immediate, recent and distant past actions in Samor. Moreover, the tone is $\mathrm{hhh}(\mathrm{hl}) 1$ in all the categories. This can be seen in the examples

RCC3S, RCC2S and RCC4S below.

RCC3S- Ká- sír- í:sy- ê- ì -hhh(hl)1

IMM PST ká- RV sír- PERF í:- EMP IMPERF ASP sy- ê- FV ì

I was writing.

RCC2S- Kó- sír- í:sy- ê- ì -hhh(hl)1

REC PST kó- RV sír- PERF í:- EMP IMPERF ASP sy- ê- FV ì

I was writing.

RCC4S- Kí- sír- í:sy- ê- ì -hhh(hl)1

DIS PST kí- RV sír- PERF í:- EMP IMPERF ASP sy- ê- FV ì I was writing.

In example RCC5S below, we can see the verb "sirisyei" as used in third person. Third person is minus a prefix.

RCC5S- Ø- sír- í:sy- ê- ì -hhh(hl)l

3P Ø- RV sír- PERF í:- EMP IMPERF ASP sy- ê- FV ì

S/he was writing.

All the examples above RCC3S, RCC2S, RCC4S and RCC5S show emphatic stress aspect in the present moment and in the immediate, recent and distant past. Tense in Samor is expressed using affixations, however aspect is indicated by varying tones on the mora.

\section{F. o) Iterative Aspect}

This is a different kind of imperfect aspect. This category refers to activities that occur repeatedly. The person involved in the action repetitively does something without stopping. The dialect marks this aspectual contrast by using the words 'ochei' and 'missing' adverbial synonyms for "so much" or "very much". If a speaker uses these expressions with a 
combination of an imperfect aspect marker, the idea of repetitiveness is achieved. See the extract 38 coded S5CG below.

Extract 38

S5CG -..Amacheasombarnotiktugul ye kabasugul ko maegubiikcheleneikakulsigaretochei, missing!

\section{Translation}

...I want to request the all the youth that when they go to school, not to be people who say I smoked so much, I smoked very much!

The examples (1) S5CG and (m) S5CG below may imply the intensity in which someone does something.

(1) S5CG- Kà- kúlóchéí

PST Kà- RV kúl- ADV óchéí

S/he smoked very much.

(m) S5CG- Kà- kúlmí:sing

PST Kà- RV kúl- ADV mí:sing

He smoked so much.

In examples (1) S5CG and (m) S5CG above, 'ochei' and 'mising' in Samor may also express the idea of repetitiveness. These words may indirectly imply that someone did something more than once hence such actions imply repetitiveness.

\section{G. p) Essive Aspect}

This category of aspectual contrast is similar to the emphatic progressive aspect since it also involves the insertion of alveolar fricative $/ \mathrm{s} /$ and the palatal approximant $/ \mathrm{j} /$. The only difference is that this category of aspectual contrast occurs without an object. To achieve the essive aspect in Samor, the final vowel /i/ is replaced by a palatal approximant /j/. This type of aspect is almost always preceded by the word 'kimi'. This word indicates what people are doing at a particular time. To show that an action is taking place in the present time, hh tone on the word 'kimi'. However, to show that the action took place in the past the tone is <ll>. See the extract 39 below.

Extract 39

S4AC: Biiktugulche mii yu ra chamgei. Amacheamwaakanee ale ngokakeetbikchemengech, ko kimacheakicheekkoekbik the kimangtaenatgaikotugul. Kongete ra ko okwek ko oobiikchemagatinkokonyiitsirikali. Magatengokwek ko matakinyorwookomiietepta ne ya ne bomayweek, nebokesesnateet, nebochorseet, nebobirisiet, neborumiik. Oloomayaniianee ko aa kirwokindengwong.

Amachekityobikcheng' enyorukolen, kimiboisyey, ma kiming' alekkapborisyeyananamisyeykityo. Oripkeisikaronkekaskelekimiborisyeymurenchoo.

Ara

amacheataachakengnganaseetasikobiitketoretgeitu gulengboisiet. Obwakeyaitekseenebokoroni. Ometenngalchechang, karibu village.

\section{Translation}

All the people who are present, how are you? I also want to say that once we have made people to be men, so we want them to be people whom we can rely on (go out with- metaphor) at all times. As from today, you are people who are supposed to respect the government/ leadership. It is required that you are not found in misbehavior, that you are in the habit of drinking, you are in sexual misconduct, you are in theft, you are in the behaviour of fighting/ beating others, you are in misconduct. No, I can't accept such misbehavior as your chief. I only want people whom when we find them they say, we are working; we are not in issues of fighting or only eating. Take care so that tomorrow we don't hear that the young men were in fighting. Therefore, I want to welcome you in the village so that we can help one another in the various activities. Come so that we can built our community. Leave too much talk, welcome to the village.

See the examples (a) S4AC and (b) S4AC below. In these examples, the speaker asserts that he expects the youth to desist from acts of fighting or eating in future. He means that he doesn't expect them to dwell on fights and greed.

(a) S4AC- Kímíbòr- í:sy- ê- y- hhlh(hl)

1PPL Kí- AUX mí- RV bòr- PERF í:- EMP IMPERF ASP syê- ESS y

We are in the act of fighting.

Note that example (a) S4AC above expresses that the youth are currently engaged in fighting. However, in example (b) S4AC below, an observer highlights that the youth were probably engaged eating. This is achieved by low tone on the two vowels ' $\mathrm{i}$ ' in the verb 'kimi' and at the same time lengthening of the vowels in the verb 'kimi'. See example (b) S4AC below.

(b) S4AC- Kìmìàm- í:sy- ê- y- 1llh(hl)

1PPL Kì:- AUX mì:- Km- RV bòr- PERF í:- EMP IMPERF ASP sy- ê- ESS y

They were in the act of fighting.

In Samor, without the auxiliary verb 'kimi' the word 'amisyey' merely expresses the essive case. This means that it functions as a noun.

\section{CONCLUSIONS}

In conclusion, the chapter began by describing the consonants and vowels in the Samor speakers. The researcher established that Samor has its own unique consonant and vowel clusters that combine to form words and sentences. In addition, the chapter gives a description of the phonological features that mark TA in Samor. These features include the following: vowel length, vowel doubling and insertion. Furthermore, the chapter discussed the role of tone in expressing the perfective and imperfective aspectual contrasts.

\section{REFERENCES}

[1] Anderson, G. (1997). Discourse Salience in Kalenjin: Inter- Clausa Syntax. Berkeley Linguistics Society; Proceedings of the TwentyThird Annual meeting of the Berkeley Linguistics Society: Special Session on Syntax and Semantics in Africa pp. 14- 25.

[2] Bao, Z. (1990). The Structure of Tone. New York: Oxford University Press.

[3] Bird, S. (1999). When Marking Tone Reduces Fluency: An Orthography Experiment in Cameroon, In a Journal Sage. Doi: 10. 1177/00238309990420010401.

[4] Booij, G. (2005). The Grammar of Words: An Introduction to Linguistic Morphology. Oxford: Oxford University Press.

[5] Bybee, J. (2003). Phonology and Language in Use. Cambridge: Cambridge University Press.

[6] Coon, J. (2013). Predication, Tenselessness, and what it Takes to be a Verb. Cambridge: Oxford University Press.

[7] Crystal, D. (2003). English as a Global Language. (Second Edition) Cambridge: Cambridge University Press. 
[8] Dai, J. (1992). Chinese Morphology and its Interface with the Syntax. Unpublished Ph.D. Dissertation, The Ohio State University.

[9] Fox, A. (2000). Prosodic Features and Prosodic Structure; The Phonology of Suprasegmentals. Oxford: Oxford University Press.

[10] Hacker, M. \& Baker, G. (2009). Rules, Grammar and Necessity. (Second Edition). United Kingdom: Wiley- Blackwell.

[11] McMahon, A. (2002). An Introduction to English Phonology. Edinburgh: Edinburgh University Press.

[12] Stewart, T. (2008). A Consumer's Guide to Contemporary Morphological Theories. OSUMPL Volume 58, Fall 2008, pp.138230.

[13] Towett, T. (1975). Kalenjin Nouns and their Classification with Notes on Phonology and a Noun List Appendix. Published MA Thesis Submitted to University of Nairobi.

[14] Yip, M. (2002). Tone. Cambridge: Cambridge University Press.

[15] Zwarts, J. (2003). The Phonology of Endo: A Southern Nilotic Language of Kenya. Netherlands: Utrecht Institute of Linguistics

\section{AUTHOR PROFILE}

1. Main Author- Daniel KandagorChepyegon, Address: P.O. BOX 536, Egerton University- Kenya

The main author is a Post Graduate student, Egerton University Department of Literature, Languages and Linguistics, Egerton University Kenya. The author is a high school teacher teaching English language and Literature. In addition, the author is also a parttimer at University of Eldoret teaching English Language and Linguistics units to prospective high school teachers pursuing Degree in Education Arts. He is a resident of Baringo County Kenya and is a person who has a passion for English Language and Linguistics. Below are his supervisors and co- author details:

2. First Supervisor- Dr. Josephine Khaemba, Lecturer Egerton University, Department of Literature, Languages and Linguistics

3. Second Supervisor- Dr. Phyllis Bartoo, Lecturer Egerton University,

Department of Literature, Languages and Linguistics 